\title{
Cardiovascular considerations of attention deficit hyperactivity disorder medications: a report of the European Network on Hyperactivity Disorders work group, European Attention Deficit Hyperactivity Disorder Guidelines Group on attention deficit hyperactivity disorder drug safety meeting - CORRIGENDUM
}

Robert M. Hamilton, Eric Rosenthal, Martin Hulpke-Wette, John G. I. Graham, Joseph Sergeant doi:10.1017/S1047951111000928, Published by Cambridge University Press, 19 July 2011.

First published online: 21 October 2011

$\mathrm{T}$ HE PAPER IS LISTED AS BEING ON BEHALF OF THE European Network for Hyperactivity Disorders and the Association of European Paediatric Cardiology. This second attribution 'Association of European Paediatric Cardiology' was deleted from the text, and should have been deleted from the author list. The author apologises for this error.

\section{Reference}

1. Robert M. Hamilton, Eric Rosenthal, Martin Hulpke-Wette, John G. I. Graham, Joseph Sergeant. Cardiovascular considerations of attention deficit hyperactivity disorder medications: a report of the European Network on Hyperactivity Disorders work group, European Attention Deficit Hyperactivity Disorder Guidelines Group on attention deficit hyperactivity disorder drug safety meeting. Cardiol Young 2011. Published by Cambridge University Press, 19 July 2011. doi:10.1017/S1047951111000928. 